\title{
Current Practices toward Fertility Issues for Young Breast Cancer Patients: A Survey of the Korean Breast Cancer Society; The SMARTSHIP Study
}

\author{
Haiyoung Son, M.D. ${ }^{1}$, Hak Min Lee, M.D. ${ }^{1}$, Yun-Jung Yang, Ph.D. ${ }^{2}$, Hyun Jo Youn, M.D., Ph.D. ${ }^{3}$, \\ Jong Won Lee, M.D., Ph.D. , Jihyoun Lee, M.D., Ph.D. ${ }^{5}$, So Youn Jung, M.D., Ph.D. ${ }^{6}$, Min Hyuk Lee, M.D., Ph.D. ${ }^{5}$, \\ Ilkyun Lee, M.D., Ph.D. ${ }^{1}$ \\ ${ }^{1}$ Department of Surgery, ${ }^{2}$ Institute of Biomedical Science, Catholic Kwandong University International St. Mary's Hospital, Catholic Kwandong University \\ College of Medicine, Incheon; ${ }^{3}$ Department of Surgery, Chonbuk National University Hospital, Chonbuk National University College of Medicine, \\ Jeonju; ${ }^{4}$ Department of Surgery, Asan medical Center, University of Ulsan college of Medicine, Seoul; ${ }^{5}$ Department of Surgery, Soonchunhyang Seou \\ Hospital, Soonchunhyang University College of Medicine, Seoul; ${ }^{6}$ Breast Cancer Center, National Cancer Center, Goyang, Korea
}

Purpose: This study aimed to investigate and analyze the current fertility-related practices for breast cancer patients; the results are intended to help improve the quality of life of young patients and survivors. Methods: This study collected voluntary responses to a questionnaire that was used to survey Korean breast cancer specialists. The questionnaire consisted of five categories: knowledge, practice behaviors regarding fertility preservation, barriers to discussing fertility preservation, attitude toward fertility issues, and demographics and medical background. Results: A total of 120 copies of the questionnaire were distributed; the response rate was $89 \%$. The section of the questionnaire regarding knowledge indicated that most respondents had adequate fertility preservation knowledge for cancer patients. However, $13.1 \%$ of the respondents indicated that they thought pregnancy increased the cancer recurrence risk. Respondents' knowledge and attitudes about fertility preservation were not correlated with actual practice. The absence of patient's expressions (24.30\%), high recurrence risk (27.10\%), insufficient time in the clinic (21.50\%), and hospital conditions such as no reproductive specialists or infertility clinic (16.82\%), were considered major barriers to discussing fertility issues. Conclusion: Although more than $50 \%$ of the respondents thought that cancer treatment is more important than fertility preservation and it is complex and difficult, the Korean breast surgical oncologists were generally encouraging when discussing fertility issues with young breast cancer patients. Hence, breast clinicians should share with young patients the updated evidence regarding the feasibility and safety of pregnancy after cancer treatment and the available options so that the best decisions can be made.

Key Words: Breast neoplasms, Fertility preservation, Survivorship

\section{INTRODUCTION}

With cancer prognosis improvement due to treatment development, quality of life has become an important problem for cancer survivors. Infertility in young cancer survivors, especially if they were childless at the time of cancer diagnosis, may impose significant psychological distress and impaired quality of life in areas of emotional well-being sexuality, and relationship [1]. The infertility risk with cancer treatments widely varies and is dependent on the patient's age as well as the

Correspondence: Ilkyun Lee, M.D., PhD.

Department of Surgery, Catholic Kwandong University International St. Mary's Hospital, Catholic Kwandong University College of Medicine, 25 Simgok-ro 100 beon-gil, Seo-gu, Incheon 22711, Korea

Tel: +82-32-290-3271, Fax: +82-32-290-3879

E-mail:iklee@ish.ac.kr, iklee68@gmail.com

The present research has been supported by Korea Breast Cancer Foundation.

Received:Sep 5, 2019 Revised: Dec 2, 2019 Accepted: Feb 18, 2020 treatment types and combinations received [2].

In Korea, over $90 \%$ of breast cancer patients survive more than 5 years after the primary treatment including surgery [3]. Moreover, the breast cancer incidence among Korean patients in their 40s is higher than that in Western countries where the proportion of premenopausal breast cancer patients is very low. The proportion of patients younger than 40 years with breast cancer in Korea is approximately 13\%. It is nearly two times higher than that in Western countries [4]. Breast cancer patients under age 40 years can achieve successful pregnancy and childbirth after treatment for breast cancer. Moreover, it is known that pregnancy itself does not increase the risk of breast cancer recurrence $[5,6]$.

Currently, many countries have conducted research regarding fertility preservation in young cancer patients, and patient referral systems [7-9]. In addition, fertility counseling and maintenance before 
cancer treatment in patients with childhood cancer have shown to improve the quality of life after cancer treatment [10].

The practice of oncologists regarding fertility preservation for cancer patients of reproductive age may depend on multiple factors, such as patient's medical and psychosocial condition [11,12], patient's knowledge [13], and physicians' knowledge about fertility preservation [14].

However, at present, there are few studies on young breast cancer patients and survivors in Korea. Furthermore, most oncologists and patients tend to focus only on cancer treatment, and experience and knowledge of fertility preservation are not adequate. Particularly, young breast cancer patients and survivors' pregnancy are unfamiliar subjects.

The purpose of this study was to investigate and analyze the current fertility-related practices for breast cancer patients, and the results are intended to help improve the quality of life of young breast cancer patients and survivors.

\section{METHODS}

This study was conducted as a questionnaire survey obtaining voluntary response from the Korean Breast Cancer Society (KBCS) members. The questionnaire used in this study was a modified form of the questionnaire used in Japanese studies, with permission obtained from the author [15]. The modified questionnaire was reconfirmed by the Korean Breast Cancer Survivor study group. The questionnaire consisted of 45 questions in five categories, namely, knowledge, practice behaviors regarding fertility preservation, barriers to discussing fertility preservation, attitude toward fertility issue, demographic and medical background (Table 1). The respondents were asked to self-evaluate their agreement with the statements using a fivegrade system (1. Strongly agree; 2. Agree; 3. Cannot decide; 4, Disagree; and 5. Strongly disagree). The questionnaire was distributed to the members of the Korean Breast Cancer Society who participated in the 2016 global breast cancer conference held at Jeju island. The questionnaire was distributed face-to-face and immediately collected after being answered. Approval for the study was obtained from our Institutional Review Board (IRB No. IS16QIS10054).

\section{Statistical analysis}

Data regarding demographic and specialty factors were summarized as frequencies and percentages. The chi-square test was used for correlation analysis between physician knowledge, attitude, and background. The Fisher's exact test was used when the frequency of each cell was less than 5 . The odds ratios and their $95 \%$ confidence intervals were calculated using multivariate logistic regression analysis that examined the association between the fertility issues for young breast cancer patients and physician's fertility preservation knowledge, attitude, age, sex, religion, duration, institute, number of staff, genetic clinic, and number of operation per month, partner, children, and death of a neighbor. Data analysis was performed using STATA (version 15.0 StataCorp LP College Station, TX, USA); $p$-values less than 0.05 were considered to represent a statistically significant difference.

\section{RESULTS}

A total of 120 copies of the questionnaire were distributed, of which 107 questionnaires were answered, resulting in a response rate of $89 \%$. Respondent demographics and characteristics are listed in Table 2. Of the respondents, 40 (37.4\%) were women, 97 (90.7\%) were breast surgeons, $6(5.6 \%)$ were medical oncologists, and 4 (3.7\%) were other specialty physicians.

Most respondents provided correct answers in the section regarding knowledge; the percentage of respondents who answered correctly ranged from $78 \%$ to $93 \%$. However, $13.1 \%$ of the respondents indicated that pregnancy increased the recurrence risk, and 9.4\% said they did not know if it increased cancer recurrence or not. Accuracy of knowledge about fertility was correlated with the number of staff where they worked $(p=0.030)$. The affiliated institution $(p=0.040)$ and the presence of a genetic counseling clinic $(p=0.040)$ were significantly correlated with a positive opinion toward fertility preservation for breast cancer patients (Table 3).

Respondents' knowledge and attitudes about the fertility preservation were not correlated with actual practice. Further, patients brought up the fertility issue more voluntarily with physicians who worked at university hospitals, who worked at institutes with more $\operatorname{staff}(\geq 4)$, and who had a spouse. The discussion frequency with patients about infertility due to cancer treatments was lower for physicians who worked at hospitals that performed more monthly surgeries. The pa- 
Table 1. Questionnaire statements

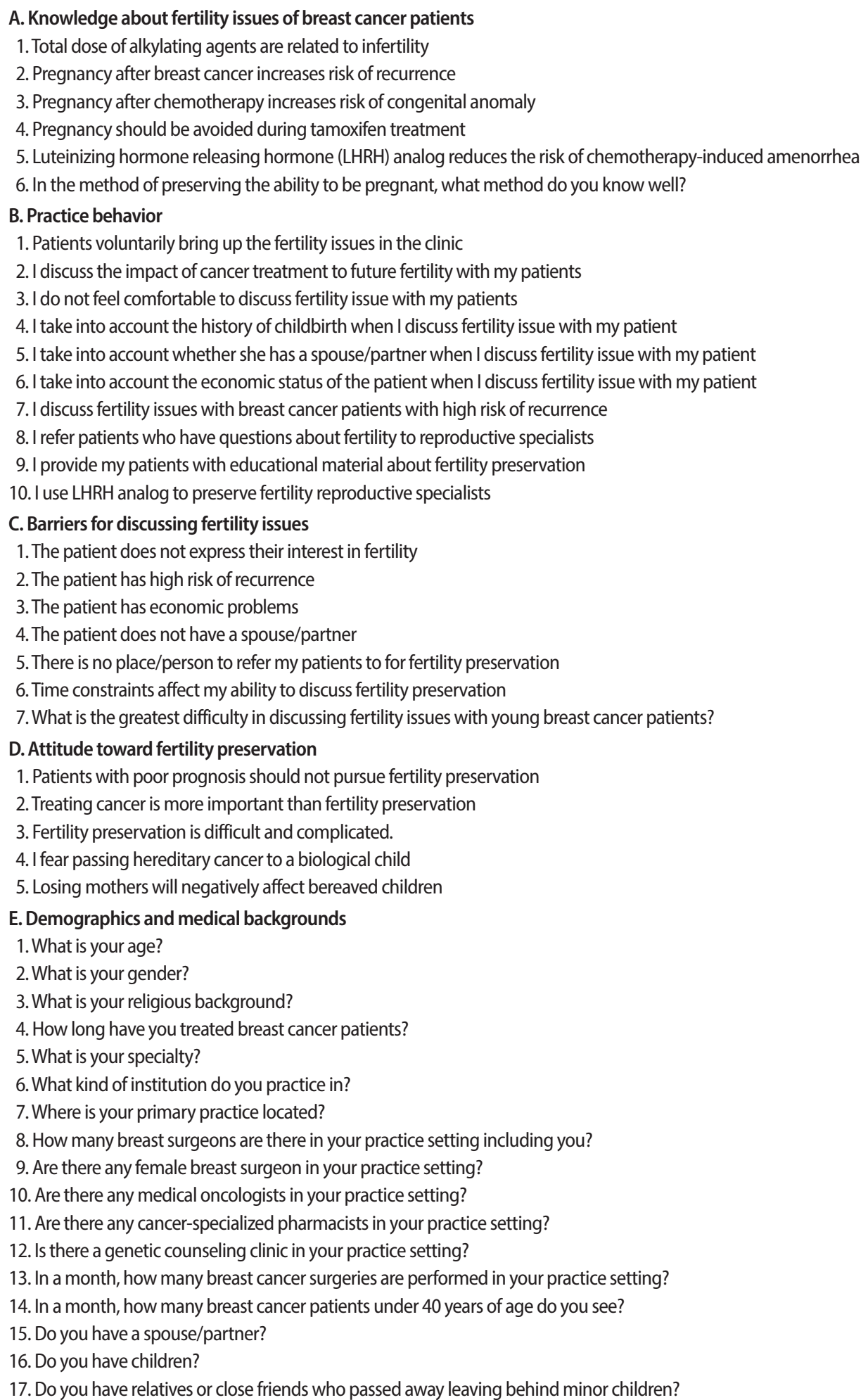

tient's economic status was considered more by physicians who worked at hospitals with a large number of breast surgical oncologists.
In case of patients with a high relapse risk, breast surgeons with more than 10 years of clinical experience are more likely to discuss fertility 
Table 2. Demographic backgrounds $(n=107)$

\begin{tabular}{|c|c|}
\hline Characteristic & №. (\%) \\
\hline \multicolumn{2}{|l|}{ Sex } \\
\hline Male & $67(62.62)$ \\
\hline Female & $40(37.38)$ \\
\hline \multicolumn{2}{|l|}{ Age (yr) } \\
\hline $30-39$ & $38(35.51)$ \\
\hline $40-49$ & $53(49.53)$ \\
\hline $50-59$ & $12(11.21)$ \\
\hline$\geq 60$ & $4(3.74)$ \\
\hline \multicolumn{2}{|l|}{ Religion } \\
\hline Protestant & $44(41.12)$ \\
\hline Catholic & $27(25.23)$ \\
\hline Buddhist & $4(3.74)$ \\
\hline Atheist & $32(29.91)$ \\
\hline \multicolumn{2}{|c|}{ Career of breast cancer treatment (yr) } \\
\hline$<5$ & $8(7.48)$ \\
\hline $5-10$ & $26(24.30)$ \\
\hline $11-15$ & $31(28.97)$ \\
\hline $16-20$ & $30(28.03)$ \\
\hline$>20$ & $12(11.21)$ \\
\hline \multicolumn{2}{|l|}{ Specialty } \\
\hline Breast surgeon & $97(90.65)$ \\
\hline Medical oncologist & $6(5.61)$ \\
\hline Others & $4(3.74)$ \\
\hline \multicolumn{2}{|l|}{ Type of affiliation } \\
\hline University hospital & $83(77.57)$ \\
\hline General hospital & $18(16.82)$ \\
\hline Special hospital & $3(2.80)$ \\
\hline Private clinic & $3(2.80)$ \\
\hline \multicolumn{2}{|c|}{ Number of Breast surgeon } \\
\hline 1 & $11(10.28)$ \\
\hline $2-3$ & $45(42.06)$ \\
\hline $4-5$ & $21(19.63)$ \\
\hline$\geq 6$ & $30(28.04)$ \\
\hline \multicolumn{2}{|l|}{ Practice region } \\
\hline Seoul & $43(40.19)$ \\
\hline Gyeonggi & 20 (18.69) \\
\hline Gangwon & $1(0.93)$ \\
\hline Chungcheong & $10(9.35)$ \\
\hline Jeolla & $17(15.89)$ \\
\hline Gyeongsang & $15(14.02)$ \\
\hline Jeju & $1(0.93)$ \\
\hline \multicolumn{2}{|l|}{ Female breast surgeon } \\
\hline Present & $73(68.2)$ \\
\hline Absent & $34(31.8)$ \\
\hline \multicolumn{2}{|l|}{ Medical oncologist } \\
\hline Present & $96(89.72)$ \\
\hline Absent & $11(10.28)$ \\
\hline \multicolumn{2}{|l|}{ Genetics clinic } \\
\hline Present & $57(53.27)$ \\
\hline Absent & $50(46.73)$ \\
\hline
\end{tabular}

Table 2. Continued

\begin{tabular}{lc}
\hline Characteristic & No. (\%) \\
\hline No. of breast cancer surgeries (per month) & \\
$1-10$ & $18(16.82)$ \\
$11-50$ & $58(54.21)$ \\
$51-100$ & $9(8.41)$ \\
$>100$ & $22(20.56)$ \\
No. of patients aged <40 (per month) & \\
$0-2$ & $26(24.30)$ \\
$3-5$ & $38(35.51)$ \\
$6-9$ & $11(10.28)$ \\
$\geq 10$ & $32(29.90)$ \\
Partner/spouse & \\
Present & $90(84.11)$ \\
Absent & $17(15.89)$ \\
Children & \\
Present & $87(81.31)$ \\
Absent & $20(18.69)$ \\
Relatives/close friends who passed away leaving behind young children \\
Present & $29(27.10)$ \\
Absent & $78(72.90)$ \\
\hline
\end{tabular}

issue. Respondents without a relative or a friend who died and left a child behind and respondents who had more than a decade of experience with breast cancer treatment referred more patients to reproductive specialists. Moreover, respondents who were religious, worked at a hospital with a genetic clinic, and did not have a relative or a friend who died and left a child behind provided patients with more informative materials about fertility preservation (Table 4).

The absence of patient's interest in fertility (24.30\%), high risk of breast cancer recurrence (27.10\%), insufficient time in the clinic (21.50\%), and hospital settings such as no reproductive specialists or infertility clinic (16.82\%) were regarded as major obstacles for fertility issue discussion (Table 5).

\section{DISCUSSION}

Recently published clinical practice guidelines by the American Society of Clinical Oncology and several other publications have highlighted fertility preservation and recommended offering fertility counseling to all young cancer patients before primary cancer treatment.

In the previous survey performed in Japan, almost one-third of the patients who expressed an interest in fertility selected a different adjuvant treatment than that treatment primarily recommended by the 
Table 3. Demographic factors associated with knowledge and attitude for fertility preservation

\begin{tabular}{|c|c|c|c|c|c|c|}
\hline \multirow[b]{2}{*}{ Factor } & \multicolumn{3}{|c|}{ Knowledge } & \multicolumn{3}{|c|}{ Attitude } \\
\hline & $\begin{array}{c}\text { No } \\
\text { knowledge }\end{array}$ & Knowledge & $p$-value & Unfavorable & Favorable & $p$-value \\
\hline \multicolumn{7}{|l|}{ Age (yr) } \\
\hline $30-39$ & 20 & 18 & $0.410^{*}$ & 12 & 26 & $0.310^{*}$ \\
\hline $40-49$ & 19 & 34 & & 15 & 38 & \\
\hline $50-59$ & 5 & 7 & & 4 & 8 & \\
\hline$\geq 60$ & 1 & 3 & & 3 & 1 & \\
\hline \multicolumn{7}{|l|}{ Gender } \\
\hline Male & 19 & 21 & 0.380 & 13 & 27 & 0.900 \\
\hline Female & 26 & 61 & & 21 & 46 & \\
\hline \multicolumn{7}{|l|}{ Religion } \\
\hline Protestant & 16 & 28 & $0.620^{*}$ & 10 & 34 & $0.120^{*}$ \\
\hline Catholic & 14 & 13 & & 10 & 17 & \\
\hline Buddhist & 2 & 2 & & 0 & 4 & \\
\hline Atheist & 13 & 19 & & 14 & 18 & \\
\hline \multicolumn{7}{|c|}{ Career of breast cancer treatment (yr) } \\
\hline$\leq 5$ & 6 & 2 & $0.310^{*}$ & 3 & 5 & $0.730^{*}$ \\
\hline $6-10$ & 11 & 15 & & 8 & 18 & \\
\hline $11-15$ & 14 & 17 & & 11 & 20 & \\
\hline $16-20$ & 10 & 20 & & 7 & 23 & \\
\hline$>20$ & 4 & 8 & & 5 & 7 & \\
\hline \multicolumn{7}{|l|}{ Type of affiliation } \\
\hline University hospital & 32 & 51 & $0.470^{*}$ & 22 & 61 & $0.040^{*}$ \\
\hline General hospital & 10 & 8 & & 10 & 8 & \\
\hline Special hospital & 1 & 2 & & 1 & 2 & \\
\hline Private clinic & 2 & 1 & & 1 & 2 & \\
\hline \multicolumn{7}{|c|}{ Number of Breast surgeon } \\
\hline 1 & 5 & 6 & $0.030^{*}$ & 3 & 8 & $0.930^{*}$ \\
\hline $2-3$ & 23 & 22 & & 16 & 29 & \\
\hline $4-5$ & 11 & 10 & & 6 & 15 & \\
\hline$\geq 6$ & 6 & 24 & & 9 & 21 & \\
\hline \multicolumn{7}{|l|}{ Genetics clinic } \\
\hline Present & 22 & 35 & 0.440 & 23 & 34 & 0.040 \\
\hline Absent & 23 & 27 & & 11 & 39 & \\
\hline \multicolumn{7}{|c|}{ No. of breast cancer surgeries (per month) } \\
\hline $0-10$ & 10 & 7 & $0.170^{*}$ & 5 & 12 & $0.890^{*}$ \\
\hline $11-20$ & 13 & 17 & & 8 & 22 & \\
\hline $21-50$ & 14 & 14 & & 9 & 19 & \\
\hline $51-100$ & 3 & 6 & & 4 & 5 & \\
\hline$>100$ & 5 & 17 & & 7 & 15 & \\
\hline \multicolumn{7}{|l|}{ Partner/spouse } \\
\hline Present & 36 & 54 & 0.320 & 27 & 63 & 0.360 \\
\hline Absent & 9 & 8 & & 7 & 10 & \\
\hline \multicolumn{7}{|l|}{ Children } \\
\hline Present & 35 & 52 & 0.430 & 26 & 61 & 0.380 \\
\hline Absent & 10 & 10 & & 8 & 12 & \\
\hline \multicolumn{7}{|c|}{ Relatives/close friends who passed away leaving behind young children } \\
\hline Present & 16 & 13 & 0.090 & 11 & 18 & 0.400 \\
\hline Absent & 29 & 49 & & 23 & 55 & \\
\hline
\end{tabular}

*Fisher's exact test. 
Table 4. Factors associated with fertility-related practice behavior

\begin{tabular}{|c|c|c|c|}
\hline Variable & & $\mathrm{OR}(95 \% \mathrm{Cl})$ & $p$-value \\
\hline \multirow{9}{*}{$\begin{array}{l}\text { B-1. Patients } \\
\text { voluntarily } \\
\text { bring up the } \\
\text { fertility } \\
\text { issues in the } \\
\text { clinic }\end{array}$} & \multicolumn{3}{|l|}{ Institute } \\
\hline & \multicolumn{2}{|c|}{$\begin{array}{c}\text { University } 1.00 \\
\text { hospital }\end{array}$} & \\
\hline & Others & $0.21(0.05-0.94)$ & 0.040 \\
\hline & \multicolumn{3}{|l|}{ No. of staff } \\
\hline & $1-3$ & 1.00 & \\
\hline & $\geq 4$ & $17.82(4.31-73.59)$ & $<0.001$ \\
\hline & \multicolumn{3}{|l|}{ Partner } \\
\hline & Yes & 1.00 & \\
\hline & No & $2.00 e-10\left(3.72 e^{-11}-1.07 e^{-09}\right)$ & $<0.001$ \\
\hline \multirow{4}{*}{$\begin{array}{l}\text { B-2. I discuss the } \\
\text { impact of cancer } \\
\text { treatment to } \\
\text { future fertility with } \\
\text { my patients }\end{array}$} & \multicolumn{3}{|c|}{ No. of OP per month operation } \\
\hline & $\leq 10$ & 1.00 & \\
\hline & $11-100$ & $0.12(0.02-0.80)$ & 0.030 \\
\hline & $>100$ & $0.05(0.01-0.62)$ & 0.020 \\
\hline \multirow{3}{*}{$\begin{array}{l}\text { B-6. I take into account } \\
\text { the economic } \\
\text { status of the } \\
\text { patient when I } \\
\text { discuss fertility } \\
\text { issue with my } \\
\text { patient }\end{array}$} & \multicolumn{3}{|l|}{ No. of staff } \\
\hline & $1-3$ & 1.00 & \\
\hline & $\geq 4$ & $3.34(1.09-10.24)$ & 0.030 \\
\hline \multirow{4}{*}{$\begin{array}{l}\text { B-7. I discuss fertility } \\
\text { issues with breast } \\
\text { cancer patients } \\
\text { with high risk of } \\
\text { recurrence }\end{array}$} & \multicolumn{3}{|l|}{ Duration (yr) } \\
\hline & $\leq 10$ & 1.00 & \\
\hline & $11-20$ & $4.96(1.56-15.83)$ & 0.010 \\
\hline & $>20$ & 12.19 & 0.070 \\
\hline \multirow{7}{*}{$\begin{array}{l}\text { B-8. I refer patients who } \\
\text { have questions } \\
\text { about fertility to } \\
\text { reproductive } \\
\text { specialists }\end{array}$} & \multicolumn{3}{|c|}{ Duration (yr) } \\
\hline & $\leq 10$ & 1.00 & \\
\hline & $11-20$ & $4.42(1.29-15.18)$ & 0.020 \\
\hline & $>20$ & 8.79 & 0.110 \\
\hline & \multicolumn{3}{|c|}{ Death of a neighbor } \\
\hline & Yes & 1.00 & \\
\hline & No & $4.23(1.27-14.17)$ & 0.020 \\
\hline \multirow{9}{*}{$\begin{array}{l}\text { B-9. I provide my } \\
\text { patients with } \\
\text { educational } \\
\text { material about } \\
\text { fertility } \\
\text { preservation }\end{array}$} & \multicolumn{3}{|l|}{ Religion } \\
\hline & Yes & 1.00 & \\
\hline & No & $0.19(0.06-0.60)$ & 0.010 \\
\hline & \multicolumn{3}{|c|}{ Gene clinic } \\
\hline & Yes & 1.00 & \\
\hline & No & $0.32(0.10-0.95)$ & 0.040 \\
\hline & \multicolumn{3}{|c|}{ Death of a neighbor } \\
\hline & Yes & 1.00 & \\
\hline & No & $3.31(1.05-10.48)$ & 0.040 \\
\hline
\end{tabular}

$\mathrm{OR}=$ odds ratio; $\mathrm{Cl}=$ confidence interval; $\mathrm{OP}=$ operation .

oncologist because of their desire to preserve fertility [16]. Therefore, young Korean breast cancer patients may choose a different adjuvant therapy if appropriate information regarding fertility preservation is provided before breast cancer treatment.

The practice of oncologists regarding fertility preservation for can-
Table 5. Barriers for discussing fertility issues $(n=107)$

\begin{tabular}{lc}
\hline Variable & No. (\%) \\
\hline The patient does not express their interest in fertility & $26(24.30)$ \\
The patient has high risk of recurrence & $29(27.10)$ \\
The patient has economic problems & $7(6.54)$ \\
The patient does not have a spouse/partner & $4(3.74)$ \\
There is no place/person to refer my patients to for & $18(16.82)$ \\
$\quad$ fertility preservation & \\
Time constraints affect my ability to discuss fertility & $23(21.50)$ \\
preservation & \\
\hline
\end{tabular}

cer patients of reproductive age may depend on multiple factors, such as patient's medical and psychosocial condition [11,12], patient's knowledge [13], and physicians' fertility preservation experience [14]. This is the first study to describe the knowledge, attitudes, and behavior of breast surgical oncologists toward fertility issues in young Korean breast cancer patients. Although a previous survey in the United States showed that many breast cancer clinicians reported that they do not have knowledge of/ or resources for fertility preservation [14], our results indicated that most respondents were well -aware of the current anti-cancer treatment impact on fertility and fertility preservation option such as oocyte cryopreservation, embryo cryopreservation, and ovarian tissue cryopreservation.

The present study showed that breast surgical oncologists generally had a positive attitude toward fertility preservation. The high response rate to this survey revealed the interest of KBCS members in fertility issue. A total of $89.7 \%(96 / 107)$ of the participants responded that they were positive in discussing fertility issue with young breast cancer patients. Although more than half of the respondents said that cancer treatment is more important than fertility preservation and that maintaining the ability to be pregnant is complicated and difficult, $40 \%$ of the respondents showed that they discussed issues related to childbearing with patients with high likelihood of relapse.

Results showed that $60 \%$ of the respondents always or often refer their patients to infertility specialists. This result was higher than in previous surveys performed in the United States (47\%) and Japan (42\%) $[7,14]$. However, these results indicate that $40 \%$ of breast surgical oncologists still do not refer patients to infertility specialists. The reason is not clear. However, $38 \%$ of the respondents answered that it is difficult for them to discuss fertility preservation because there are no fertility-related department or fertility experts at their hospitals.

Results of a study by Quinn et al. [6] showed that $47 \%$ of the re- 
sponding oncologists often refer their patients to infertility specialists; however, these results indicate that more than half of the oncologists do not refer their patients. The likelihood of referring patients to infertility specialists was predicted by the sex and attitudes toward fertility preservation of oncologists. Female physicians are possibly more aware of patients' desire for family and information regarding fertility-related issues. Velikova et al. [17] performed a qualitative study of quality of life issues and found that female oncologists were more willing to discuss sexuality and felt that such discussions had high impact on the survivors' quality of life. However, there was no correlation in our study.

A high disease recurrence risk was considered the greatest barrier to discussing fertility for physicians, which was similar to the results of other studies $[11,12]$. When the patient had advanced breast cancer with a high likelihood of recurrence, both the patient and physician tended to refrain from discussing the future ability to achieve pregnancy. In this case, patient care should include not only referral to reproductive specialists but also informational, psychological, social, and religious (if applicable) support. Other reasons that were barriers to discussing fertility were patients not expressing an interest in fertility, insufficient medical consultation time, and hospital circumstances. Nevertheless, patients who did not voluntarily express an interest in fertility may have not known about the possibility of infertility due to cancer treatment or may have not known about fertility preservation. Therefore, if information had been provided about these issues, the results would have been different.

This study revealed that it is necessary to improve medical care by readjusting medical fees, increasing research regarding patient needs, and creating a system for patient referrals.

Forman et al. [18] showed that reluctance among physicians to discuss fertility preservation or to refer patients to fertility specialists is due to the associated costs. However, in our survey, only $6 \%$ of the respondents considered the patients' economic circumstances. This seemed to be because most patients in Korea have private insurance that pays for their medical costs.

This study was limited by the small sample size and patients not being surveyed. Further investigations of patients' needs are required because patients and physicians often have discordant perceptions of patients' needs and problems. Another limitation of this study is that the results from the surveys may be biased due to the diverse roles of a breast surgical oncologist since each institution has their own different clinical practice, which may result in differences in the perceptions of fertility issues. This study will be meaningful as a study of the physician's view of young breast cancer patients from the initial breast cancer diagnosis to further treatment plans.

In conclusion, although more than $50 \%$ of the respondents believed that cancer treatment is more important than fertility preservation and that fertility preservation is complex and difficult, Korean breast surgical oncologists were generally positive when discussing fertility issues with young breast cancer patients. Breast clinicians should share with young patients the updated evidence regarding the feasibility and safety of pregnancy after cancer treatment and the available options for fertility preservation so that the best decisions can be made.

\section{CONFLICT OF INTEREST}

The authors declare that they have no competing interests.

\section{ACKNOWLEDGMENTS}

The authors sincerely thank the members of the Korean Breast Cancer Survivor study group (Study of Multi-disciplinARy Teamwork for breast cancer survivorSHIP: SMARTSHIP) who assisted the survey and the KBCS members who were willing to respond to the questionnaire. The present research has been supported by the Korea Breast Cancer Foundation.

\section{REFERENCES}

1. Carter J, Rowland K, Chi D, Brown C, Abu-Rustum N, Castiel M, et al. Gynecologic cancer treatment and the impact of cancer related infertility. Gynecol Oncol 2005;97:90-5.

2. Shapiro CL, Recht A. Side effect of adjuvant treatment of cancer breast. N Engl J Med 2001;344:1997-2008.

3. Kim KS, Kim Z, Shim EJ, Kim NH, Jung SY, Kim JS, et al. The reality in the follow-up of breast cancer survivors: survey of Korean breast cancer society. Ann Surg Treat Res 2015;88:133-9.

4. 2018 Breast cancer facts \& figures. Korea Breast Cancer Society. http://www.kbcs.or.kr/journal/file/181004.pdf. Accessed Oct 4th, 
2018.

5. Kranick JA, Schaefer C, Rowell S, Desai M, Petrek JA, Hiatt RA, et al. Is pregnancy after breast cancer safe? Breast J 2010;16:404-11.

6. de Bree E, Makrigiannakis A, Askoxylakis J, Melissas J, Tsiftsis DD. Pregnancy after breast cancer. A comprehensive review. J Surg Oncol 2010;101:534-42.

7. Quinn GP, Vadaparampil ST, Lee JH, Jacobsen PB, Bepler G, Lancaster J, et al. Physician referral for fertility preservation in oncology patients: a national study of practice behaviors. J Clin Oncol 2009; 27:5952-7.

8. Bastings L, Baysal O, Beerendonk CC, Braat DD, Nelen WL. Referral for fertility preservation counselling in female cancer patients. Hum Reprod 2014;29:2228-37.

9. Kim J, Mersereau JE. Early referral makes the decision-making about fertility preservation easier: a pilot survey study of young female cancer survivors. Support Care Cancer 2015;23:1663-7.

10. Letourneau JM, Ebbel EE, Katz PP, Katz A, Ai WZ, Chien AJ, et al. Pretreatment fertility counseling and fertility preservation improve quality of life in reproductive age women with cancer. Cancer 2012; 118:1710-7.

11. Arafa MA, Rabah DM. Attitudes and practices of oncologists toward fertility preservation. J Pediatr Hematol Oncol 2011;33:203-7.

12. Collins IM, Fay L, Kennedy MJ. Strategies for fertility preservation after chemotherapy: awareness among Irish cancer specialists. Ir Med J 2011;104:6-9.
13. Peate M, Meiser B, Friedlander M, Zorbas H, Rovelli S, Sansom-Daly U, et al. It's now or never: fertility-related knowledge, decision-making preferences, and treatment intentions in young women with breast cancer - an Australian fertility decision aide collaborative group study. J Clin Oncol 2011;29:1670-7.

14. Quinn GP, Vadaparamil ST, King L, Miree CA, Wilson C, Raj O, et al. Impact of physicians' personal discomfort and patient prognosis on discussion of fertility preservation with young cancer patients. Patient Educ Couns 2009;77:338-43.

15. Shimizu C, Bando H, Kato T, Mizota Y, Yamamoto S, Fujiwara Y. Physicians' knowledge, attitude, and behavior regarding fertility issues for young breast cancer patients: a national survey for breast care specialists. Breast Cancer 2013;20:230-40.

16. Kubo A, Koido K, Sawada M, Ryushima Y, Shimizu C, Kato T, et al. Survey on oncologists-provided information on treatment-related infertility to breast cancer patients. Gan To Kagaku Ryoho 2012;39: 399-403.

17. Velikova G, Awad N, Coles-Gale R, Wright EP, Brown JM, Selby PJ. The clinical value of quality of life assessment in oncology practice: a qualitative study of patient and physician views. Psychooncology 2008; 17:690-8.

18. Forman EJ, Anders CK, Behera MA. Pilot study of oncologists regarding treatment-related infertility and fertility preservation in female cancer patients. J Reprod Med 2009;54:203-7. 